\title{
Barriers and opportunities for palliative care development in the Eastern Mediterranean Region
}

\section{Authors:}

Ibtihal Fadhil, PhD. Regional Adviser Noncommunicable diseases, World Health Organization, Eastern Mediterranean Regional office, Cairo, Egypt

Gemma Lyons, MPH. Technical Officer, World Health Organization, Eastern Mediterranean Regional office, Cairo, Egypt

Sheila Payne, PhD (full professor). International Observatory on End of Life Care, Faculty of Health and Medicine, Lancaster University, Lancaster, Lancashire, LA1 4YT, United Kingdom

\section{Abstract}

The 22 countries of the World Health Organization's Eastern Mediterranean Region (EMR) are experiencing an increase in the burden of non-communicable diseases, including cancer. Of the six WHO regions, the EMR is projected to have the highest increase in incidence of cancer over the next 15 years. Furthermore, most cancers are diagnosed at a late stage, resulting in a lower cancer survival rate than in Europe and the Americas. Therefore, with increasing numbers of cancer deaths, it is important that palliative care is available to relieve suffering for patients with advanced disease and at the end of life.

In the Region, it is evident that the palliative care offer is patchy and inconsistent. Gaps include: the lack of inclusion within national policies and limited partnership working; insufficient palliative care education for health professionals and volunteers; lack of public awareness; and a gap in access to essential pain relief medicines. Addressing these barriers would result in improvements to palliative care delivery in the EMR. To this end, this review explores the current status of palliative care in the region, including challenges and opportunities. It explores data and evidence from published literature, WHO meeting reports, cancer control mission reports, and the WHO global non-communicable diseases country capacity survey. 
It is apparent that many steps can be taken to improve provision across the region. Palliative care should be included in curricula for health professionals training. Policy and legislative changes are required to increase access to opioids. Additionally, improved standardized national data collection and research is important to monitor the situation over time and to future-proof policy interventions accordingly.

There is a great need to develop and expand palliative care services in the EMR, and to gain national leverage to do so. Advocacy and political influence are required to ensure sustainability, equitability and high-quality of palliative care services. 


\section{Introduction}

Palliative care is an approach that improves the quality of life of patients - adults and children and their families facing the problems associated with life-threatening illness, through the prevention and relief of suffering. This is undertaken through early identification and assessment and treatment of pain and other related issues, physical, psychosocial and spiritual $^{1}$. In this context of this paper, the focus is on end-of-life care and not supportive care throughout the patients' illness and treatment. Palliative care for chronic life-limiting health problems is unmet in most parts of the world. There is increased recognition and awareness of the need for palliative care for non-communicable diseases (NCDs) especially cancer.

On the global level, the World Health Organization (WHO) explicitly recognizes that palliative care is part of the comprehensive services required for NCDs through the Global Action Plan for the Prevention and Control of NCDs 2013-2020 2 . Furthermore, the 2014 World Health Assembly Resolution 67.19 on Strengthening of Palliative Care as a Component of Comprehensive Care Throughout the Life Course recognizes that palliative care, when indicated, is fundamental to improving the quality of life, well-being, comfort and human dignity for individuals, being an effective person-centered health service that values patients' need to receive adequate, personally and culturally sensitive information on their health status, and their central role in making decisions about the treatment received ${ }^{3}$. In addition, palliative care is encompassed in the definition of universal health coverage ${ }^{4}$ and the WHO global strategy on people-centered and integrated health services offers a framework for the strengthening of palliative care programs across diseases ${ }^{5}$.

Cancer is the fourth ranked cause of death in the region, following cardiovascular diseases ${ }^{6}$, however the Eastern Mediterranean Region is witnessing a progressive increase in cancer burden. In 2012, there were 555,318 new cases of cancer and 367,441 cancer deaths, however, it is projected that in 2030 , there will be 961,000 new cancer cases and 652,000 cancer deaths in the region ${ }^{7}$ ). Furthermore Of the six WHO regions across the globe, the EMR is projected to have the highest increase in cancer incidence over the next 15 years ${ }^{6}$.

Some countries in the region have improved early detection of cancer, especially in the case of breast cancer ${ }^{8}$, however in most of the region cancer patients seek treatment when they are at an advanced stage and their cure is improbable even with the best treatments. Accordingly, palliative care is essential and it usually presents itself as the only viable option for those patients. Yet, in EMR palliative care needs, to a large part, are unaddressed in many countries. Where present, palliative care services are generally at an early stage of development and not integrated within the national health care system. Many challenges exist within the areas of governance, human resources, training and medication availability for palliative care. 
Improving access to essential palliative care services is one of the regional strategic interventions under the area of health care in the Regional Framework for Action (RFFA). The framework is a road map for countries in the Region to enable them to implement the United Nations Political Declaration on Prevention and Control of NCDs. It provides strategic interventions and indicators to assess country progress by 2018 in the areas of: governance; prevention and reduction of risk factors; surveillance, monitoring and evaluation; and health care ${ }^{9}$. The regional strategic direction for cancer control and prevention in EMR focuses on three key areas: capacity building of the providers; improving accessibility of pain management; and providing home-based / community palliative care services ${ }^{10}$. Palliative care is also an integral part of the new initiative on scaling-up cancer care in EMR ${ }^{11}$.

The aim of this review is to explore the relevant dimensions of palliative care in the EMR and identify potential barriers to development and to make recommendation for future action. The review is compiled from multiple sources, including WHO regional reports, cancer plans and strategy documents; desk review on studies and research on palliative care in the EMR; and data extracted from the NCD Country Capacity Survey 2015 (CCS).

The CCS is conducted periodically by WHO and it has been administered in 2010, 2013 and 2015. It is completed by the NCD manager within each country's ministry of health or national agency. The survey is composed of 5 modules assessing national capacity for NCD prevention and control, and it includes 4 questions related to palliative care. In 2015, 21 out of 22 countries in the Eastern Mediterranean Region completed the survey, and data compiled and reported ay global and regional levels.

\section{Search Strategy and Selection Criteria [Panel]}

This paper is envisioned as a scoping review and presented as a narrative review of the evidence using systematic procedures but we do not claim it to be a systematic review. The following approaches were adopted for a wide-ranging database search to identify papers of relevance. A generic database search used the terms: 'supportive care', 'palliative care', 'endof-life care', 'cancer', 'cancer trends', 'epidemiology', 'public health', and 'Eastern Mediterranean (and with the names of the 22 countries within the region)', within their title, abstract, or keywords. Our sources included the following searches engines: 'Google', CINAHL, and MEDLINE. In addition, the following websites were searched: World Health Organisation, World Wide Hospice and Palliative Care Alliance, Lien Foundation, International Association of Hospice and Palliative Care, Pain and Policy Studies Database, and European Association for Palliative Care (where blogs from EMR have been published). The opioid and morphine 
mapping data are derived from the WHO based on data published by the International Narcotics Control Board (INCB) which is the independent and quasi-judicial control organ monitoring the implementation of the United Nations drug control conventions. As the review was intended to be wide ranging, the inclusion criteria include qualitative, quantitative, and mixed method research, including WHO data monitoring reports, policy documents, and international and country specific reports written in English and Arabic between 2000 onwards. Papers written in languages other than English or Arabic, prior to 2000 or not involving cancer patients were excluded.

\section{Burden of Cancer in the Eastern Mediterranean Region} Cancer incidence in the region is projected to increase substantially over the next 15 years (figure 1). There are already over 500,000 new cancer cases every year and more than 360,000 deaths ${ }^{7}$. However, by 2030 , projection models indicate that there will be almost a million new diagnoses per year and around 650,000 deaths ${ }^{7}$, thus increasing the need for palliative care provisions.

The most common cancers in the region are Breast, Colorectal, Lung, Liver and Bladder cancer. Combined, these five make up $40 \%$ of cancer in the region ${ }^{7}$ ). However, when the rates are age standardised, Prostate cancer has the second highest incidence, and Bladder cancer is sixth.

The incidence and mortality rates for these cancers are illustrated in table 1 . Breast cancer alone accounts for around 100,000 new cancer cases per year in the region, three times more than any other cancer. Furthermore, breast cancer has the highest mortality rate, causing over 42,000 deaths per year, followed by Lung cancer $(29,000)$ and Liver cancer $(28,000)$.

The majority of cancer cases are diagnosed at a relatively advanced/late stage - where cure is improbable even with the best treatments - accordingly, the need for palliative care is critical in EMR (table 2) ${ }^{7}$. As would be expected from the late stage of diagnosis, cancer survival rates are low in the region compared to the Western regions, such as the Americas and Europe (figure 2). In the EMR, risk of getting cancer before the age of 75 is $12.9 \%$, whereas the risk is twice as high at $24.5 \%$ in the Americas. Despite this, risk of dying prematurely from cancer is more similar, at $9.1 \%$ and $10.6 \%$ in the EMR and Americas, respectively ${ }^{7}$. 


\section{Palliative Care in the Region}

In most EMR countries palliative care services are at the initial stages of development. Some countries have more developed services than others; however the general level of palliative care is basic. Based on a palliative care mapping exercise in $2006^{12}$, the Worldwide Palliative Care Alliance (WPCA) categorized countries by level of palliative care development again in $2011^{13}$, using the four categories from the original study, although two of these groups were further subdivided into $a$ and $b$ categories. The categories range from group 1 being countries with no known activity to group 4 being the countries approaching integration. Compared to global distribution, a greater proportion of EMR countries are at an early stage of development of palliative care provisions (figure 3). While 6 countries in the region have no known services, the majority of countries in the EMR fall into group 3(a) with localised hospice-palliative care provision (table 3$)^{13,14}$. There was a notable increase in palliative care provision during the 5 year period $(2006$ - 2011), with 5 countries in the region moving from group 2 (capacity building) to group 3 (isolated provision) during that time.

Furthermore, the Quality of Death Index reiterates the limited palliative care services in the Region. The first version, published in 2010 did not include any EMR countries ${ }^{15}$; however the second version in 2015 included six countries from the Region ${ }^{16}$. The index compared 80 countries worldwide based on 20 qualitative and quantitative indicators, across five domains. One high income country was included (Saudi Arabia), which ranked lowest on the index of the 35 high income countries compared, with an indicator of $30.8 \%$. Saudi Arabia ranked 60th out of the 80 countries, overall. Morocco and Egypt, included as low-income countries, both scored higher than that of Saudi Arabia. Iraq, included as a middle income country, had the lowest Quality of Death score of all 80 countries included. The report found that palliative care can be improved through national policies, training for healthcare staff, subsidies for care, and access to opioids and psychological support.

\section{Policies \& Plans}

Access to palliative care services is a major challenge in the region, where as it is estimated that only $5 \%$ of adults who are in need of palliative care, receive it ${ }^{17}$. One of the key strategic interventions in the RFFA is to improve access to palliative care services including an operational national palliative care plan. The WHO NCD Country Capacity Survey (CCS) in 2015 questioned the inclusion of palliative care as part of national NCD action plan ${ }^{18}$. Ten countries reported having included it (table 4). Of those, eight reported including palliative care as part of their National NCD Action Plan. Kuwait and Tunisia reported to have included palliative care, even though their national NCD plan is currently under development and not yet endorsed. Both of those countries have a standalone Palliative Care policy/plan. 
Furthermore, funding for palliative care is limited in the region. In the CCS, only 12 EMR countries reported to have funding available for palliative care (table 4). All of the low income countries in the region reported having no funding available for palliative care services, although three of the six countries did have funding available for other NCD-related services, such as early detection and health care.

\section{Availability of palliative care services}

Primary care practitioners in the region are well-placed to provide palliative care services to their communities ${ }^{19}$, however services are currently lacking. The CCS collected country data on whether at least $50 \%$ of the population has access to public palliative care services through primary care ${ }^{18}$. Only Saudi Arabia and Syria reported to have primary care based palliative care services available to at least $50 \%$ of NCD patients within the public health system. The survey also asked about access to home based care. Three countries (Saudia Arabia, Syria and Qatar) reported having home-based palliative care available to cover at least half the population. However, given the current conflict in Syria, availability of palliative care services is likely to be limited.

Home-based care has a strong potential in the Region due to the structure of the community and also the strong family bonds ${ }^{20}$. Furthermore, Middle Eastern culture - which places strong emphasis on family and social bonds - is conducive to the establishment of home-based palliative care services. However, this model of care requires a supportive environment and a strong link between health care systems and home-based support. It is essential that there are medical and nursing services (i.e. primary care general practitioners and community nurses) that can visit the patient at home and/or be easily consulted by telephone. It also requires training and development of health care professionals, care givers and volunteers ${ }^{21}$.

Furthermore, access to palliative care services within secondary level care varies among EMR countries. Examples of hospital/clinic-based services in the region are outlined below:

- In Bahrain palliative care is offered in the main hospital (Salmynia Medical Complex SMC) which has a team of oncologists, palliative care specialists, medical officer, residents and nurses. It has two weekly follow-up clinics, one weekly pain clinic and a hotline for homecare problems ${ }^{22}$. Since 2010 there has been little further progress due to staff shortages and limited funding.

- In Jordan, palliative care is offered through two hospitals: the King Hussein Cancer Centre (KHCC) and Al Basheer Hospital. KHCC is a comprehensive cancer centre in Amman. Meanwhile, Al Basheer hospital's oncology unit provides support service to several hundred patients each year ${ }^{23,24}$. A recent study has evidenced the improvement 
in symptoms experienced thorough delivery of outpatient palliative care services in Jordan ${ }^{25}$.

- In Egypt, there are pain clinics at most cancer care centers; however, no complete multidisciplinary palliative care team is functioning. Recently, a centre has been established in Kasr AlAiny Hospital at Cairo University ${ }^{26}$.

- In Oman, palliative care is still in its early stages. The medical oncology department at the main hospital is currently providing the essential palliative care services given to terminally ill, but mainly given on day-care basis ${ }^{26,27}$.

- Saudi Arabia has been developing palliative care services since 1992 and has expanded to the whole kingdom ${ }^{22}$. Currently there were more than 15 cancer centers and wellestablished palliative care units with integrated home-based care, providing services for 500 patients a year ${ }^{22}$ ). The units are made up of multidisciplinary teams incorporating a variety of professionals such as physicians, nurses, social workers, dieticians, physical therapists, home care health nurses, health educators, pharmacists and religious authorities ${ }^{28}$. However, more work is needed to raise awareness of palliative care, and to improve pain management legislation ${ }^{22}$.

\section{Partnerships and networks}

In most countries in the EMR, Non-Governmental Organisations (NGOs) provide a variety of important services. They support to cancer patients' families financially; endorse training programs; and support cancer centres by providing equipment and medications. They often play a key role in palliative care services, given the limited government funds. The longestablished institutions in the region are usually operated by voluntary, not-for-profit, charitable associations with financial support from the Ministry of Health as well as donations from the community ${ }^{22,29}$.

In Pakistan there are 20 cancer care centers: 17 private and three governmental. Treatment is mainly supported by local charity organizations. A few hospices are present and supported by private nongovernmental organizations ${ }^{30}$.

In Jordan, in addition to existing hospitals, palliative care services are offered by a number of non-profit CSOs organizations including Al-Malath Foundation for Humanistic Care ${ }^{23,24}$. The foundation is a nongovernmental, volunteer organization established in 1993. It has a hospice with a team of volunteering nurses that provides social, spiritual, psychological, and nursing care for patients during their end of life period. The Palliative Care Jordanian Society is an NGO established in $\mathbf{2 0 1 0}$ which focuses on increasing the culture of palliative care through training, education, advocacy and networking ${ }^{31}$. 
The Lebanese Center for Palliative Care, Balsam, is a non-governmental organization that provides holistic support to patients dealing with life-threatening illness by providing medical services as well as psychological, social, practical, and spiritual support within the family and home environment ${ }^{32,33,34}$. Capacity building in palliative care is also provided to ensure effective delivery of in-hospital and community palliative care.

In Palestine, the idea of initiating palliative care services has been proposed by an NGO known as Al-Sadeel Society, which is currently the first and only official Palliative Care Society in the Palestinian National Authority. Currently, the organisation delivers an educational and awareness program at Beit Jala governmental hospital. Also, in cooperation with the Middle East Cancer Consortium, they have supported a number of physicians to train abroad ${ }^{35,36}$.

\section{Human Resources / Training programs}

There is variability across the Region in availability of human resources with palliative care expertise (physicians, nurses, medical assistants, care workers and volunteers), and access to appropriate training programs.

In the last ten years a number of short courses have been delivered in the region, by various international organizations [Middle East Cancer Consortium (MECC), the US National Cancer Institute ( $\mathrm{NCl})$, The Oncology Nursing Society (ONS) in the USA, The American Society of Clinical Oncology (ASCO), EPEC (Education in palliative and end of life care), and the Institute for Palliative Medicine at the San Diego Hospice]. These are being delivered to scale up the number of well-trained palliative care professionals in the Region.

Furthermore, WHO Eastern Mediterranean Regional Office has been delivering an annual Training of Trainers (ToT) Workshop on Palliative Care since 2010, targeting various health care providers. The program is delivered jointly with Regional partners such as the Gulf Federation for Cancer Control (GFCC). The most recent TOT program was held in Kuwait in November $2015^{26}$. The program is a generalist orientation in which health professionals are exposed to palliative care concept and principles. It focuses on the use of the WHO protocol for integration of palliative care in primary health care, in order to expand the services and empower primary health care staff.

At the country level, a proposal for a national palliative care programme in Saudi Arabia was developed in 2004, which included systematic training programmes for healthcare staff ${ }^{37}$. The country has successfully accredited palliative care in their medical specialist training and they have developed a well-structured one-year Palliative Care fellowship ${ }^{30}$. The structured fellowship programme will be extended to 2 years and it is accredited by the Saudi Medical 
Council as a speciality. A 3-month certificate in palliative care has also been developed, as well as ongoing symposiums and local short courses, and a 2.5 year Masters programme in Spiritual Care accredited by Durham University ${ }^{30}$. In Jordan, a 3-month diploma in Palliative Care Management and Spiritual Care Communication has been accredited by the Ministry of Higher Education. The King Hussain Cancer Centre also provides a nine month diploma in palliative care in partnership with Jordan University, Yale University and USAID ${ }^{38,39}$. Furthermore, a series of short in-house short courses are available ${ }^{38,39}$. However, Palliative care is not yet integrated into medical and nursing curricula ${ }^{40}$.

However, despite these recent developments in training, most countries in the EMR are still facing shortages of a well-trained workforce and often an unequal distribution of human resources, as well as the absence of a multi-disciplinary approach to palliative care. For example, one challenge is that the existing health education systems do not support palliative care as a priority area. Training on palliative care is not a mandatory in most countries as part of graduate or undergraduate professional education. Very few medical and nursing schools have incorporated palliative care into their curriculum, and most existing residency programs in oncology, medicine, family medicine and paediatrics do not include palliative care in their core curriculum; therefore medical residents and fellows are seldom examined in it. In some EMR countries palliative care services are available despite having no specialist trained staff. In Palestine, for example, there are two oncology centers, including palliative care services, however there are no specialized trained palliative care doctors or healthcare staff.

\section{Pain management}

Pain management is an essential aspect of palliative care; it alleviates the suffering of those who are at progressive stages of illness so that their quality of life is improved ${ }^{41}$.To this end, the WHO Essential Medicine List describes fourteen palliative care medications, and access to opiate pain relief is one of the 25 indicators in the Global Monitoring framework for NCDs; however there is a number of challenges affecting the availability and access to these medicines in the $E M R{ }^{42,43,44}$.

Pain relief, in most cases, is achieved through the administration of opioids, which are available throughout the region; however, there is government legislation in place for the prescription of generic or proprietary opioid medication ${ }^{45}$. The global data indicates that opioid consumption is relatively low in in the Eastern Mediterranean Region, compared to the rest of the world (table 5) ${ }^{46,47}$. Of countries that had Morphine available in 2014 , the mean consumption was $0.15 \mathrm{mg} /$ capita, while the global average in for the same time period was 40 times greater at $6.11 \mathrm{mg} /$ capita. A significant but less pronounced difference was recorded in Methadone consumption which globally was double that of the regional figure. However, the mean is 
heavily skewed by Iran where the consumption was $9.3 \mathrm{mg} /$ capita. Overall, the Total Morphine Equivalence in the region was 6 times lower than the global mean.

There are several challenges which impact on the adequate availability of and access to pain relief medications, namely: inadequate or overly strict legislation; unbalanced policies; limitations on available forms of medication especially oral opioids; lack of supply and distribution systems; limitations on who can prescribe; insufficient knowledge on the use of controlled medicines; and inappropriate attitudes towards controlled medicines ${ }^{46,47}$.

To overcome some of these challenges, WHO has been working jointly with Member States and other partners since 2010, to review and modify national legislations related to availability and affordability of opioid for pain management. A series of training workshops and country assessments were conducted to: support countries to assess the local situation, including analysis of legislation and policies; updating national essential medicines lists; training on data reporting; and supporting health institutions to establish adequate curricula on pain management ${ }^{26}$.

\section{Discussion}

Palliative care in most of the Eastern Mediterranean Region remains at an early stage of development, with insufficient strategic planning by governments for palliative care services. This is not only due to lack of resources across much of the region, but also the complex political situations and weak health system coupled with conflict affecting some countries of the region. More than half of all countries in the region are experiencing emergencies, including three countries in complex emergencies with active conflicts and ten countries facing protracted crises. Eight of these countries currently have UN humanitarian Strategic Response Plans (Afghanistan, Iraq, Libya, Occupied Palestinian Territory, Somalia, Sudan, Syria and Yemen). These situations are having a significant impact on health systems, affecting healthcare access including palliative care and medication supply ${ }^{48,49}$.

The lack of national plans and policies has been identified. Countries in the EMR should strive to develop national palliative care plans, integrated within their NCD strategy in-line with the local context and health needs. While current funding in countries may be limited, policy makers could work with national and international partners to secure funding and improve capacity.

Palliative care is provided by a mixture of NGOs, charitable religious associations, and private and government hospitals. At the system level, partnership working between these organisations can help to facilitate sharing of resources, provide standardized training, and increase capacity at within countries. Furthermore, collaboration between countries will strengthen palliative care provision at the regional level. We have highlighted examples of 
where mixed models of statutory, for-profit and philanthropic funding have enabled countries to develop and sustain palliative care services.

In the region, the majority of the population have limited or no understanding of palliative care services. Also, the lack of awareness amongst policy-makers, health professionals and the public about what palliative care is, and the benefits it can offer to patients and health systems, is a key challenge. Moreover, there are misconceptions about palliative care, combined with social cultural barriers such as beliefs about death and dying ${ }^{26}$. For example, the culture of the region has long-standing fatalistic beliefs about death ${ }^{20}$. Therefore there is little public demand for these services or even resistance to accepting them when they are offered. Information should be made available through government or community portals to raise public understanding of the benefits of palliative care. Patients with serious and life limiting cancers need to know that they can receive access to high quality and compassionate palliative care wherever they are living.

Globally, the issue of professional education and accreditation of palliative medicine is an important topic ${ }^{50,51}$. In the last few years there has been a notable increase in palliative care training courses in the region, however, there remains a lack of specialist palliative care professionals and limited volunteers. It is therefore recommended that countries in the region provide current healthcare professionals with accredited training on palliative care, both as part of undergraduate and graduate education. Furthermore, a module on advancing palliative care is included in the new edition of the ESMO/ASCO Global Curriculum in Medical Oncology (GC) in 2016, which could be very useful for the development on training in the EMR ${ }^{52}$. In addition, training of community volunteers should be encouraged to increase capacity in the provision of practical and psychosocial support for palliative care patients. This strategy has been proven successful in other low and middle income countries globally ${ }^{53}$.

To improve pain management, countries can review legislation on availability and affordability of opioids. This can be implemented at the national level through a situational analysis of legislation and policies. In Lebanon this has been done through development of a national committee ${ }^{54}$ Additionally, countries should update national essential medicines lists and support health institutions when establishing adequate curricula on pain management, using the WHO country checklist $55,56,57$. WHO has developed a list of Essential Medicines, which includes opioids and medicines for other common symptoms of palliative care. A national committee

Integrating palliative care into national health policies is fundamental for countries to improve access to palliative care. This is coupled with the need for countries to have funding mechanisms in place for palliative care. A financing allocation can be undertaken using a 
resource-stratification approach to the cancer care pathway, incorporating supportive and palliative care ${ }^{58}$. More advocacy activity is required to sensitize policy-makers and decisionmakers to promote investment and secure the resources required for palliative care; this is the case for low and middle-income countries globally ${ }^{59}$.

There are several limitations in this review. Notably, there is a lack of research and published literature on palliative care in most of the Region. The data that is available, such as the CCS, provides a very narrow insight into the picture of palliative care provision, as it is limited to four closed questions on the topic. There is a potential bias as we focused on publications in English, future reviews should include material published in French and Arabic languages. Furthermore, information gathered from meeting reports is not scientifically rigorous; however it provides a contextual and real-world insight into service availability, partnerships, training and barriers to pain relief. Overall, this review provides a synthesis of the available information, including that gathered through WHO meeting reports, thus starting to build a picture of the status of palliative care in the EMR. In future studies, it is important to collect primary data from service providers (physicians and nurses) and service users (patients and family members). Population level retrospective surveys of bereaved family members are used for national quality improvement initiatives of end of life care in four countries (USA, UK, Ireland and Italy), this can be considered in the EMR.

\section{Conclusion}

At the end-stage of life, palliative care cancer patients experience a high level of distress. There is a need for greater attention to developing these services in the EMR. The review found limited published scientific evidence. There is a need to leverage more national data and establish comparable evidence bases to drive policy. There are indicators of palliative care program growth, educational initiatives and capacities building in certain countries but questions remain about their sustainability. Overall, the review has identified a pressing need to expand access to palliative care services and to encourage the engagement of hospitals in quality improvement initiatives.

\section{Declaration of Interests}

No funding required. The authors declared no conflicts of interest.

\section{Contributors' statement}

IF laid the writing of the manuscript. GL contributed to write the manuscript. SP contributed to editing. All authors reviewed and commented on revisions of the paper. 


\section{References}

1) WHO Definition of Palliative Care. Geneva: World Health Organization; 2016 (http://www.who.int/cancer/palliative/definition/en/, accessed 15 February 2016).

2) WHO Global action plan on the prevention and control of NCDs 2013-2020. Geneva: World Health Organization; 2013 (http://www.who.int/nmh/publications/ncd-actionplan/en/, accessed 15 February 2016).

3) Strengthening of palliative care as a component of comprehensive care throughout the life course. Geneva: World Health Organization; 2016

(http://apps.who.int/gb/ebwha/pdf_files/WHA67/A67_R19-en.pdf, accessed 16 February 2016).

4) What is universal coverage? Geneva: World Health Organization; 2016 (http://www.who.int/health_financing/universal_coverage_definition/en/, accessed 15 February 2016).

5) WHO global strategy on people-centered and integrated health services. Geneva: World Health Organization; 2016 (http://www.who.int/servicedeliverysafety/areas/peoplecentred-care/en/, accessed 15 February 2016).

6) Cancer topic webpage, World Health Organization Regional Office for the Eastern Mediterranean; 2016 (http://www.emro.who.int/health-topics/cancer/index.html, accessed 15 June 2016).

7) GLOBOCAN 2012: Estimated cancer Incidence, Mortality and Prevalence Worldwide in 2012, Population Factsheets(http://globocan.iarc.fr/Pages/fact sheets population.aspx; accessed 15 June 2016)

8) El Saghir N, Assi HA, Jaber SM, et al; Outcome of Breast Cancer Patients Treated outside of Clinical Trials, J Cancer, 2014, 5(6):491-498.

9) Regional framework for action. Cairo: WHO Regional Office for Eastern Mediterranean; 2015 (http://www.emro.who.int/noncommunicable-diseases/framework-foraction/index.html, accessed 17 February 2016).

10) Strategy for cancer prevention and control in the Eastern Mediterranean Region 20092013. Cairo: WHO Regional Office for Eastern Mediterranean; 2010 (http://www.emro.who.int/noncommunicable-diseases/summaries/strategy-canceremr.html, accessed 19 February 2016).

11) Fadhil, I. WHO recent initiatives in cancer prevention and control, priorities and update. Cairo: WHO Regional Office for Eastern Mediterranean; 2014 (http://www.cancerburdengcc.com/app/webroot/js/ckfinder/userfiles/files/Cancer/Presentations/Day1/Session1/ 02-Ibtihal\%20Fadhil.pdf, accessed 18 February 2016). 
12) Wright M, Wood J, Lynch T \& Clark D. Mapping levels of palliative care development: a global view. J Pain Symptom Manage. 2008 May; 35(5):469-85.

13) Mapping Levels of Palliative Care Development: A Global Update. Worldwide Palliative Care Alliance, 2011

14) Lynch $T$, Connor $S \&$ Clark D. Mapping levels of palliative care development: a global update. J Pain Symptom Manage. 2013 Jun;45(6):1094-106.

15) The quality of death: Ranking end-of-life care across the world; The Economist Intelligence Unit, 2010 (http://graphics.eiu.com/upload/eb/qualityofdeath.pdf; accessed 6 October 2016).

16) The 2015 Quality of Death Index Ranking palliative care across the world; The Economist Intelligence Unit, 2015 (http://www.apcp.com.pt/uploads/2015-EIU-Quality-of-Death-IndexOct-6-FINAL.pdf) ; accessed 15 June 2016)

17) Global Atlas of Palliative Care at the End of Life. London: Worldwide Hospice Palliative Care Alliance; 2014.

18) Assessing National Capacity for the Prevention and Control of Noncommunicable Diseases: Report of the 2015 country capacity survey in the Eastern Mediterranean Region; World Health Orgaization; published 2016.

19) Murray SA \& Osman H., Primary palliative care: the potential of primary care physicians as providers of palliative care in the community in the Eastern Mediterranean region. East Mediterr Health J. 2012 Feb;18(2):178-83. Review.

20) Silbermann M, Arnaout $M$ \& Daher M. Palliative cancer care in Middle Eastern countries: accomplishments and challenges. Annals of Oncology 2012; 23 (3): 15-28.

21) Kumar, S. Concept Note: Palliative Care - VII. Cairo: WHO Regional Office for Eastern Mediterranean; 2014.

22) Abu Zeinah GF, Al-Kindi SG, Hassan AA. Middle East Experience in Palliative Care; American Journal of Hospice \& Palliative Medicine (2012) 30(1): 94-99.

23) Stjernsward J, Ferris FD, Khleif SN. Jordan palliative care initiative: a WHO demonstration project. J Pain Symptom Management (2007) 33(5): 628-633. Review.

24) Bingley, A \& Clark, D. Palliative Care in Jordan. In: Palliative Care in the Region Represented by the Middle East Cancer Consortium: A Review and Comparative Analysis. National Cancer Institute. Bethesda, MD, USA; 2008: 83-94.

25) Shamieh $O$, Khamash $O \&$ Khraisat M, Impact of outpatient palliative care (PC) on symptom burden in patients with advanced cancer at a tertiary cancer center in Jordan. Support Care Cancer. 2016 Sep 7. [Epub ahead of print]

26) Fadhil, I. Regional consultation on WHO palliative care programme manual and Training of Trainers (TOT) workshop on palliative care. Cairo: WHO Regional Office for Eastern Mediterranean; 2015. 
27) Mahfudh SS. Historical perspectives and trends in the management of pain for cancer patients in Oman. Asian Pacific Journal of Cancer prevention (2010) 11:93-96

28) Almobarak, F. Exploring the perspectives of nurses, physicians, and healthcare administrators in Saudi Arabian hospitals on palliative care and palliative care nursing; Journal of Health Specialities (2014) 2(2): 54-58

29) Kronfol, NM. Delivery of health services in Arab countries: a review. Eastern Mediterranean Health Journal 2012; 18(12): 1229-1238. Cairo: WHO Regional Office for Eastern Mediterranean; 2012 (http://www.emro.who.int/emhj-volume-18-2012/issue12/08.html, accessed 18 February 2016).

30) Report on the Palliative care training workshop. Cairo: WHO Regional Office for Eastern Mediterranean; 2011

(http://applications.emro.who.int/docs/IC_Meet_Rep_2011_EN_14522.pdf, accessed 18 February 2016).

31) Anna Lindh Foundation Webpage: Palliative Care Jordanian Society (available: http://www.annalindhfoundation.org/members/jordan-palliative-care-painmanagement-society, accessed 20 July 2016)

32) The Lebanese Center for Palliative Care - Balsam, Webpage (available: http://www.balsam-lb.org/, accessed 20 July 2016)

33) Osman H \& Ramia JA. PA28 Assessing physicians' perception of home based palliative care services in the beirut area. BMJ Support Palliat Care. 2015 Apr;5 Suppl 1:A28. doi: 10.1136/bmjspcare-2015-000906.88.

34) Osman H. Development of palliative care in Lebanon. Obstacles and opportunities. J Med Liban. 2015 Jan-Mar;63(1):42-6.

35) Thweib N. Quality of life of Palestinian cancer patients. J Pedriatr hematol Oncol. 2011; 33 (suppl.1): S68-S69

36) Shawawra M \& Khleif AD. Palliative care situation in Palestinian Authority. J Pedriatr hematol Oncol. 2011; 33 (suppl.1): S64-S67.

37) Al-Shahri MZ, Brown SM, Bruera ED. Palliative Care: Proposal for a national program in Saudi Arabia. Editorial. Saudi Med J 2004; Vol. 25 (12) 1791-1795

38) Palliative \& Home Care Education Program: Health care professionals (booklet), King Hussein Cancer Foundation. Available via email: mf.10931@khcc.jo and sturki@khcc.jo

39) Palliative \& Home Care Education Program: Family, caregivers \& volunteers (booklet) King Hussein Cancer Foundation. (Available https://www.scribd.com/document/327749427/Caregivers-Booklet, accessed 19 October 2016)

40) Palliative Care in Jordan: Accomplishments and Challenges. Chapter 9 in Palliative Care to the Cancer Patient. Author: Mohammad Al-Qadire et al. Editor: Michael Silbermann. 2014 Nova Science Publishers, Inc. ISBN: 978-1-63117-709-5 
41) Oxford Textbook of Palliative Medicine (4th edition); 2015; Oxford University Press

42) WHO Model List of Essential Medicines, 19th List. Geneva: World Health Organization; 2016 (http://www.who.int/medicines/publications/essentialmedicines/en/ accessed 16 February 2016).

43) NCD Global Monitoring Framework. Geneva: World Health Organization; 2016 (http://www.who.int/nmh/global_monitoring_framework/en/, accessed 18 February 2016).

44) Stjernsward J. Foley K \& Ferris F. The public health strategy for palliative care. Journal of Pain and Symptom Management (2007) 33, 514-520.

45) Report on the Expert meeting on scaling-up cancer care in the Eastern Mediterranean Region. Cairo: WHO Regional Office for Eastern Mediterranean; 2014 (http://applications.emro.who.int/docs/IC_Meet_Rep_2014_EN_15570.pdf, accessed 18 February 2016).

46) Pain \& Policy Studies Group Webpage (Available: http://www.painpolicy.wisc.edu/opioid-consumption-data, accessed 6 October 2016)

47) WHO Briefing Note on Access to Controlled Medicines: Balanced Policy Approach Between Responsible Use and Misuse; World Health Organization Regional Office for the Eastern Mediterranean, 2016.

48) The Work of WHO in the Eastern Mediterranean Region: Annual Report of the Regional Director 2015, WHO Regional Office for the Eastern Mediterranean (available http://applications.emro.who.int/docs/RD Annual Rep 201619004 EN.pdf?ua=1, accessed 19 October 2016)

49) WHO Address to the Regional Committee for the Eastern Mediterranean, Sixty-third Session Cairo, Egypt, 3 October 2016, Dr Margaret Chan Director-General (available: http://applications.emro.who.int/docs/Other Speech Messages RC63 DG opening 20 16 EN 19100.pdf?ua=1, accessed 13 October 2016)

50) Centeno C, Bolognesi D \& Biasco G. Comparative analysis of specialization in palliative medicine processes within the World Health Organization European region. Journal of Pain and Symptom Management. 2015; 49(5):861-70

51) Carrasco JM, Lynch T, Garralda E et al. Palliative Care Medical Education in European Universities: A Descriptive Study and Numerical Scoring System Proposal for Assessing Educational Development. Journal of Pain and Symptom Management. 2015 Oct; 50(4):516-23.

52) Dittrich $C$, Kosty $M$, Jezdic $S$ et al. ESMO/ASCO recommendations for a Global Curriculum (GC) in medical oncology-edition 2016. Annals of Oncology, 2016 Aug;27(8):1378-81. 
53) Steedman MR, Hughes-Hallett T, Knaul FM, Knuth A, Shamieh O \& Darzi A. Innovation can improve and expand aspects of end-of-life care in low- and middle-income countries. Health Aff (Millwood). 2014 Sep;33(9):1612-9.

54) Osman H, Abboud M, El Zein L, Ghusn H, Hanna J, Kanazi G. Setting practice standards for palliative care in Lebanon--recommendations of the Subcommittee on Practice -National Committee for Pain Control and Palliative Care. J Med Liban. 2013 OctDec;61(4):199-203.

55) Caraceni, A, Hanks G, Kaasa S, et al. Use of opioid analgesics in the treatment of cancer pain: evidence-based recommendations from the EAPC. Lancet. Oncol. 13, e58-68 (2012).

56) World Health Organization. WHO Model List of Essential Medicines (adults), 19th ed. Geneva (2015). http://www.who.int/medicines/publications/essentialmedicines/en/ (accessed July 8, 2015).

57) World Health Organization. Ensuring balance in national policies on controlled substances: guidance for availability and accessibility of controlled medicines. Geneva: WHO (2011). http://whqlibdoc.who.int/publications/2011/9789241564175_eng.pdf (accessed July 8, 2015).

58) Distelhorst SR, Cleary JF, Ganz PA, et al. Optimisation of the continuum of supportive and palliative care for patients with breast cancer in low-income and middle-income countries: executive summary of the Breast Health Global Initiative, 2014. Breast Health Global Initiative Global Summit on Supportive Care and Quality of Life Consensus Panel Members. Lancet Oncol. 2015 Mar;16(3):e137-47. doi: 10.1016/S1470-2045(14)704577. Review.

59) Cleary J, Ddungu H, Distelhorst SR. Supportive and palliative care for metastatic breast cancer: resource allocations in low- and middle-income countries. A Breast Health Global Initiative 2013 consensus statement. BO. Breast. 2013 Oct;22(5):616-27. doi: 10.1016/j.breast.2013.07.052. Epub 2013 Aug 21. Review. 


\section{Figures and Tables}

Figure 1: Projected Cancer Burden in EMR: \% increase 2012 - 2030 (incidence).

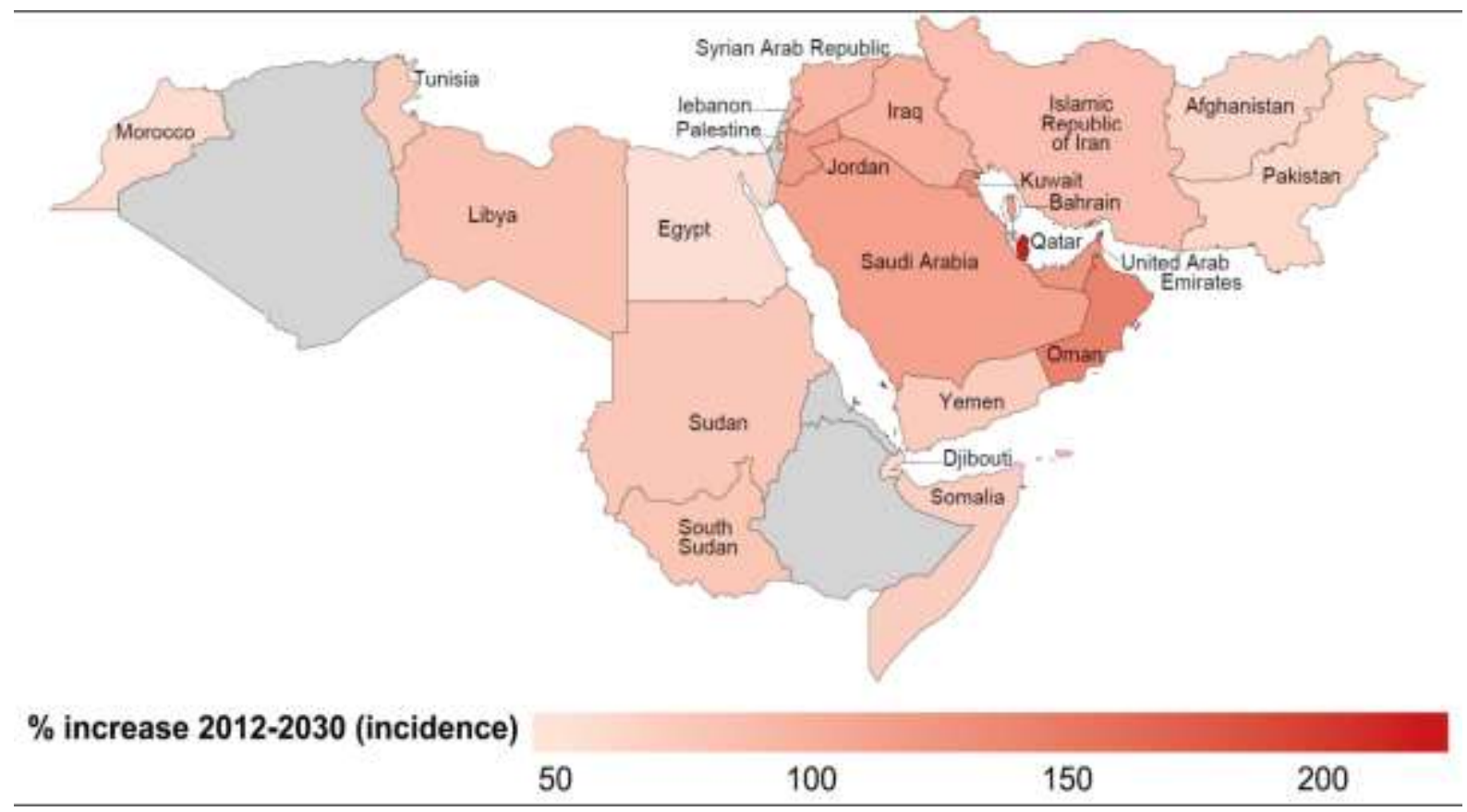

Table 1 - Age Standardised Incidence and Mortality Rates for five most common cancers in Eastern Mediterranean Region ${ }^{7}$ )

\begin{tabular}{lll}
\hline Cancer & \multicolumn{2}{l}{ Age Standardized Rate per 100,000 } \\
\cline { 2 - 3 } & Incidence & Mortality \\
Breast & 41.9 & 18.6 \\
Prostate & 9.7 & 6.2 \\
Lung & 7.9 & 7.1 \\
Colorectal & 7.4 & 4.9 \\
Liver & 7.1 & 6.8 \\
\hline
\end{tabular}

Table 2: Stage of diagnosis in breast and cervical cancer, as reported by population-based registries (Saudi Arabia, Egypt and United States of America)

Breast cancer Cervical cancer

\begin{tabular}{|c|c|c|c|c|c|c|}
\hline Stage & USA & $\begin{array}{l}\text { Saudi } \\
\text { Arabia }\end{array}$ & Egypt & USA & $\begin{array}{l}\text { Saudi } \\
\text { Arabia }\end{array}$ & Egypt \\
\hline
\end{tabular}




\begin{tabular}{|c|c|c|c|c|c|c|}
\hline Localized Stage & $65 \%$ & $29 \%$ & $\begin{array}{l}25.5 \\
\%\end{array}$ & $58 \%$ & $35.5 \%$ & $35.9 \%$ \\
\hline Advanced Stage & $30 \%$ & $55 \%$ & $58 \%$ & $33 \%$ & $51 \%$ & $53.2 \%$ \\
\hline $\begin{array}{l}\text { Advanced with } \\
\text { Metastasis }\end{array}$ & $5 \%$ & $16 \%$ & $\begin{array}{l}16.5 \\
\%\end{array}$ & $9 \%$ & $14 \%$ & $10.9 \%$ \\
\hline
\end{tabular}

Figure 2 - Risk of premature cancer and cancer death (<75 years) by WHO region, Globocan figures, $2012^{7}$

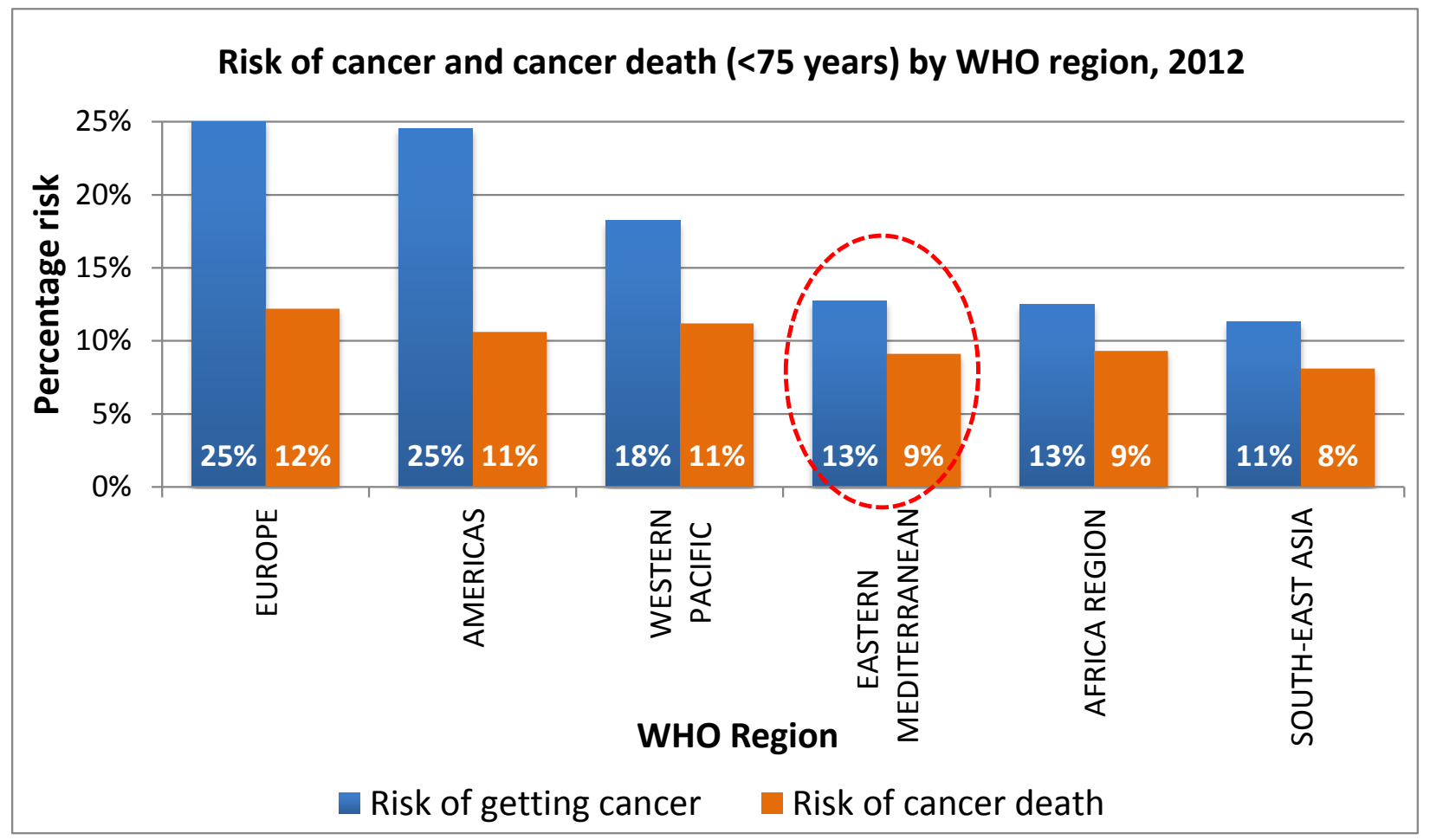

Source: Graph produced from Globocan figures ${ }^{7}$

Table 3 - WPCA categorization of palliative care development for EMR countries, 2011

\begin{tabular}{ll}
\hline Group & Countries \\
\hline $\mathbf{1 - N o}$ Known Activity & Afghanistan \\
& Djibouti \\
& Libya \\
& Somalia \\
& Syria \\
& Yemen \\
$\mathbf{2 - C a p a c i t y ~ B u i l d i n g ~}$ & Oman \\
& Palestine \\
\hline
\end{tabular}




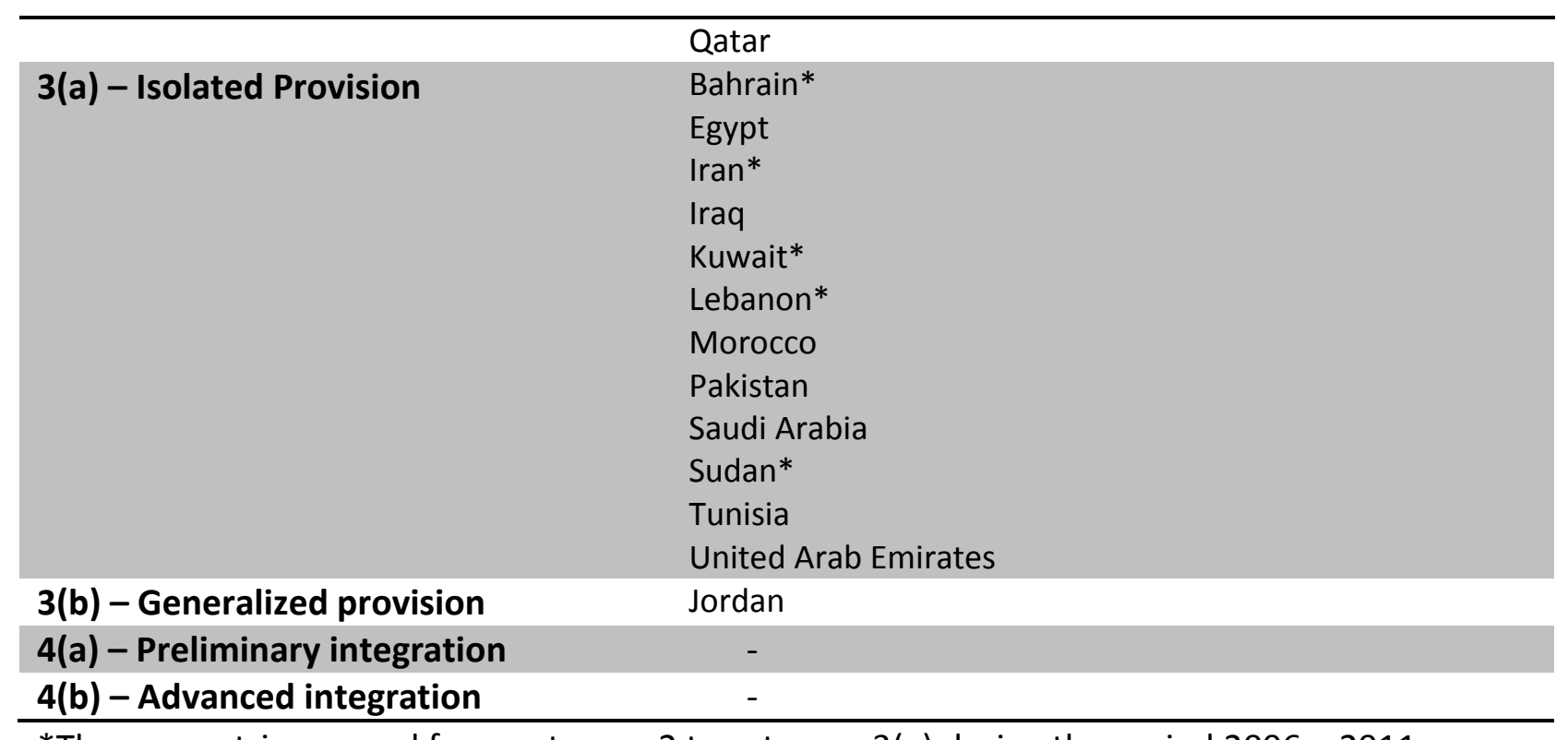

*These countries moved from category 2 to category 3(a) during the period $2006-2011$.

Figure 3-Comparison of distribution of countries

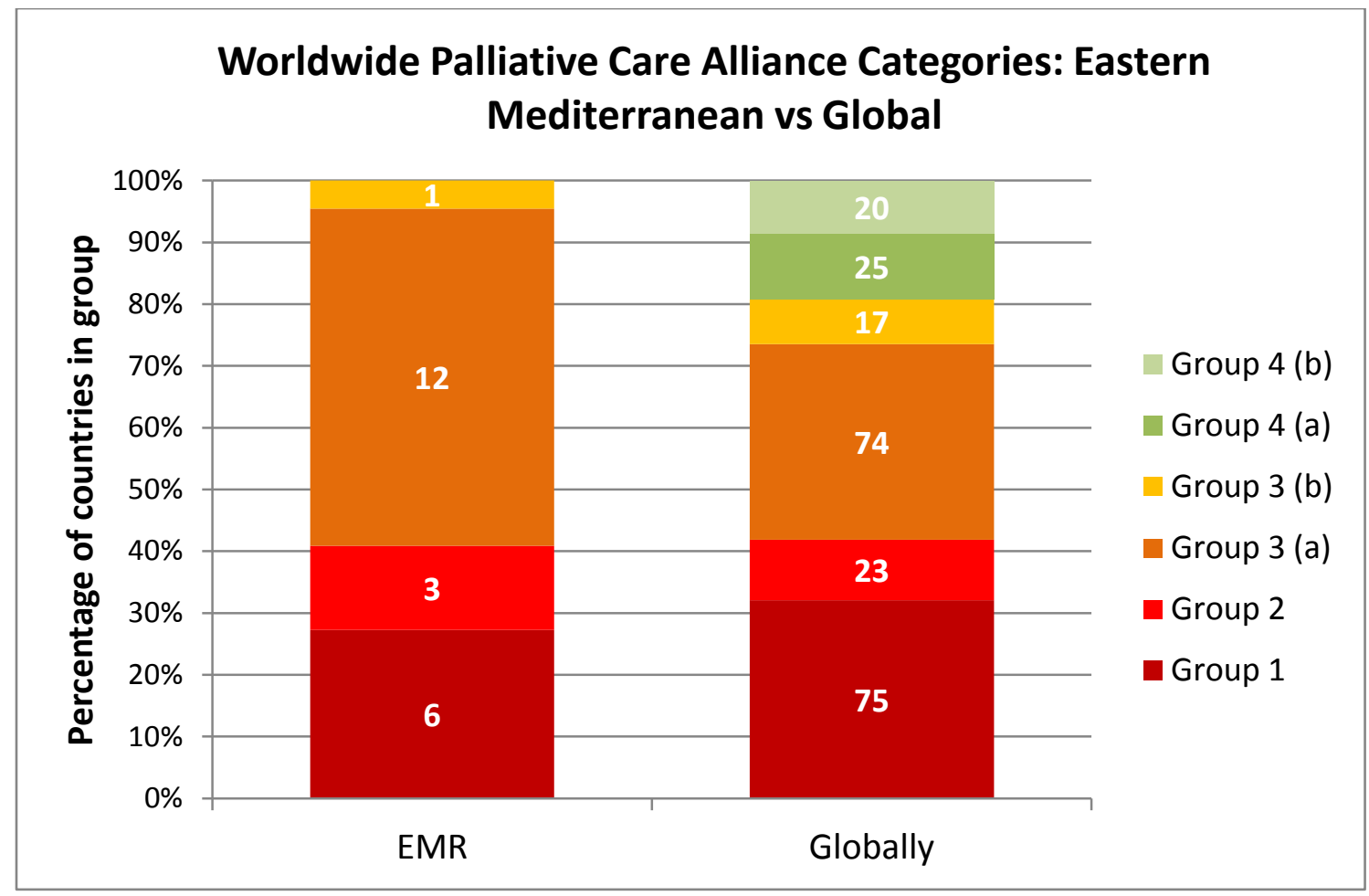

Source: Graph produced from WPCA data ${ }^{13}$

Table 4 - Inclusion of Palliative Care in National NCD Action Plan and Funding availability ${ }^{18}$ 


\begin{tabular}{|l|c|c|}
\hline \multicolumn{1}{|c|}{ Country } & $\begin{array}{c}\text { Inclusion of Palliative Care in } \\
\text { National NCD Action Plan }\end{array}$ & Funding for Palliative Care \\
\hline Afghanistan & No & No \\
\hline Bahrain & Yes & Yes \\
\hline Egypt & No & No \\
\hline Iran (Islamic Republic of) & Yes & No \\
\hline Iraq & Yes & No \\
\hline Jordan & No & No \\
\hline Kuwait & Yes & Yes \\
\hline Lebanon & Yes & Yes \\
\hline Libya & No & Yes \\
\hline Morocco & Yes & Yes \\
\hline Oman & No & Yes \\
\hline Pakistan & No & No \\
\hline Palestine & No & Yes \\
\hline Qatar & Yes & Yes \\
\hline Saudi Arabia & Yes & Yes \\
\hline Somalia & No & No \\
\hline Sudan & No & No \\
\hline Syrian Arab Republic & No & Yes \\
\hline Tunisia & Yes & Yes \\
\hline United Arab Emirates & Yes & Yes \\
\hline Yemen & No & No \\
\hline Source: Data from & NHO & \\
\hline
\end{tabular}

Source: Data from WHO Country Capacity Survey, 2015.

Table 5 - Consumption of Opioids in EMR and globally, in 2014 46, 47

\begin{tabular}{|l|c|c|c|}
\hline \multicolumn{1}{|c|}{ Opioid medicine } & $\begin{array}{c}\text { Global consumption } \\
\text { (mg/capita) }\end{array}$ & $\begin{array}{c}\text { EMR consumption } \\
\text { (mg/capita) }\end{array}$ & Ratio Global / EMR \\
\hline Fentanyl & 0.2090 & 0.00612 & $34: 1$ \\
\hline Hydro-morphone & 0.6245 & 0.00263 & $237: 1$ \\
\hline Methadone & 4.7753 & 2.40147 & $2: 1$ \\
\hline Morphine & 6.11 & 0.15393 & $146: 1$ \\
\hline Oxycodone & 11.7755 & 0.08077 & $1.5: 1$ \\
\hline Pethidine & 1.0323 & 0.68823 & $6: 1$ \\
\hline $\begin{array}{l}\text { Total Morphine } \\
\text { Equivalence }\end{array}$ & 61.66 & 10.56249 & \\
\hline
\end{tabular}

